\title{
Webs y portales de transparencia para la participación ciudadana en la gestión de las relaciones públicas con los stakeholders locales
}

\section{Transparency and citizen participation web pages and portals for managing public relations with local stakeholders}

\author{
Pilar Paricio-Esteban; Teresa Bruno-Carlos; Elvira Alonso-Romero; María P. García- \\ Alcober
}

Cómo citar este artículo:

Paricio-Esteban, Pilar; Bruno-Carlos, Teresa; Alonso-Romero, Elvira; García-Alcober, María P. (2020). “Webs y portales de transparencia para la participación ciudadana en la gestión de las relaciones públicas con los stakeholders locales". Profesional de la información, v. 29, n. 3, e290335.

https://doi.org/10.3145/epi.2020.may.35

Artículo recibido el 12-11-2019

Aceptación definitiva: 04-06-2020
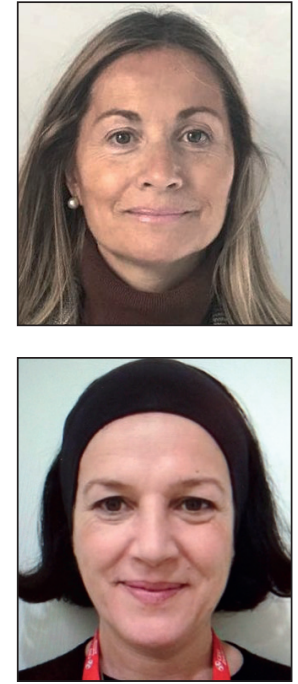

Pilar Paricio-Esteban

https://orcid.org/0000-0002-8831-9352

Universidad Cardenal Herrera-CEU

Dto. de Com. Audiovisual y Publicidad Obs. de Gobernanza, Transparencia y RSC Luis Vives, 1. 46115 Alfara del Patriarca (Valencia), España pparicio@uchceu.es

\section{Elvira Alonso-Romero $\square$ http://orcid.org/0000-0002-6438-3149 \\ Universidad Cardenal Herrera-CEU Dto. de CC. Políticas, Ética y Sociología Obs. de Gobernanza, Transparencia y RSC Luis Vives, 1. 46115 Alfara del Patriarca (Valencia), España elvira.alonso@uchceu.es}

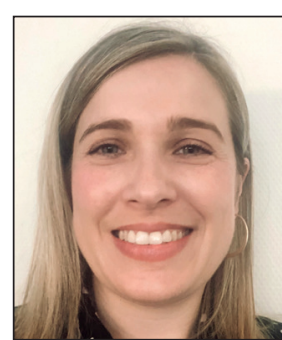

Teresa Bruno-Carlos

https://orcid.org/0000-0002-1885-1976

Universidad Cardenal Herrera-CEU Dto. de CC. Políticas, Ética y Sociología Obs. de Gobernanza, Transparencia y RSC Luis Vives, 1. 46115 Alfara del Patriarca (Valencia), España teresa.brunocarlos@uchceu.es

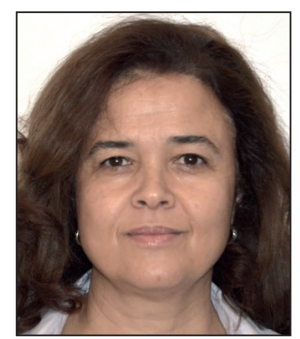

María P. García-Alcober https://orcid.org/0000-0001-5342-3320

Universidad Cardenal Herrera-CEU Departamento de Economía y Empresa Luis Vives, 1. 46115 Alfara del Patriarca (Valencia), España maria.garcia3@uchceu.es

\section{Resumen}

El objeto de la investigación es conocer si las webs y portales de transparencia municipales son utilizados como herramientas de Relaciones Públicas orientadas al diálogo con los públicos locales. Para ello, se ha realizado un análisis de contenido utilizando como base la metodología del Mapa InfoParticipa y un análisis de regresión, centrándose el estudio en los ayuntamientos de la Comunidad Valenciana. En el trabajo se han identificado 5 modelos predominantes de webs y portales de transparencia: web independiente, apartado en web, sede electrónica, plantilla de la Diputación provincial y plantilla del Gobierno de España. En todos los modelos se observa, en general, un bajo nivel de cumplimiento de indicadores de transparencia y participación. El modelo más utilizado por los ayuntamientos es la sede electrónica, siendo el que peores niveles de cumplimiento registra para todos los públicos. La web independiente y el apartado en el sitio web, que son las fórmulas más utilizadas en los ayuntamientos de más de 50.000 habitantes, favorecen más la relación con los ciudadanos y asociaciones locales. Los medios y los órganos de participación son los públicos menos atendidos desde una perspectiva de las Relaciones Públicas en todos los modelos. En el análisis de las regresiones lineales, se evidencia que la web independiente y el apartado en web son significativos en el conjunto de la población, junto con el primer modelo y las plantillas de la Diputación en ayuntamientos más pequeños. El uso de las últimas es una oportunidad para facilitar las relaciones con los stakeholders locales en los municipios de menos de 20.000 habitantes, que cuentan con menos recursos para la elaboración de diseños propios. 


\title{
Palabras clave
}

Relaciones públicas; Ayuntamientos; Comunicación pública; Transparencia; Web; Portal de transparencia; Stakeholders; Agentes interesados; Actores implicados; Participación; Ciudadanía; Mapa InfoParticipa.

\begin{abstract}
The aim of this research is to determine whether web pages and portals aimed at municipal transparency are in fact used as public relations tools directed at liaison with local stakeholders. The study focuses on the municipalities of the Autonomous Community of Valencia, using a methodology based on the InfoParticipa map via a content and regression analysis. Five main models of transparency web pages and portals were identified in this study, all showing, in general, a low level of compliance with transparency and participation indicators. The online site, although the most heavily used by the municipalities, was the model with the lowest levels of compliance. Separate websites or website sections, the model most widely used by municipalities with more than 50,000 inhabitants, greatly favor relations with citizens and local associations. In contrast, the media and participatory bodies are the stakeholders that are less well addressed from the perspective of public relations in the transparency web pages and portals adopting all the models. The results obtained by linear regression analysis show that independent websites and website sections are significant for the whole dataset. Nevertheless, for small municipalities, independent websites and the Diputación (provincial government) template are the most significant models. The latter model provides the opportunity to address stakeholder relationships for small municipalities that cannot afford to draw up their own designs.
\end{abstract}

\section{Keywords}

Public relations; Municipalities; Public communication; Transparency; Web pages; Municipal transparency portals; Stakeholders; Participation; Citizenship; InfoParticipa map.

\section{Introducción}

La evolución de la democracia contemporánea hacia el impulso de la transparencia y participación implica un mayor protagonismo de la comunicación pública, como relación entre la institución y sus stakeholders. Tomando como referencia esta idea de relación, Canel-Crespo define la comunicación de las administraciones como

"el intercambio de realidades cognoscitivas que se realiza entre las organizaciones públicas, y entre éstas y los públicos clave" (Canel-Crespo, 2018, p. 43).

La comunicación de las instituciones lleva aparejada un factor de obligatoriedad. Con la aprobación de la Ley 19/2013, de 9 de diciembre, de transparencia, acceso a la información pública y buen gobierno (España, 2013), y las legislaciones autonómicas en la materia, la obligatoriedad de la comunicación pública ha adquirido una dimensión más amplia, sumándose España al fenómeno de “eclosión de las leyes de transparencia pública” (Fernández-Ramos, 2018, p. 220).

Como consecuencia de esta legislación han proliferado webs y portales de transparencia. Más allá de las obligaciones legales, podrían ser instrumentos clave en el desarrollo de modelos de relaciones públicas bidireccionales y dialógicos con los ciudadanos y otros públicos (Kent; Taylor, 1998; Grunig; Hunt, 2003; Xifra, 2011; Otero-Alvarado; Pulido-Polo, 2018).

La proximidad y cercanía de las entidades locales conlleva una mayor capacidad de generar relaciones de confianza con la ciudadanía. Por ello, Campillo-Alhama subraya la importancia de establecer una "red de relaciones en la administración municipal" (2013, p. 79). En este contexto, la gestión de la comunicación entendida como relación adquiere un papel fundamental en la interacción de las organizaciones municipales con sus públicos. Para ello, como apunta Peytibi (2016), los valores de la transparencia y la participación se han posicionado como fundamentales en la gestión de las relaciones públicas municipales. En este sentido,

"las ideas de transparencia, participación y colaboración se han instalado en la agenda política/administrativa en un momento en que se hace necesario un impulso hacia la innovación en el sector público" (Criado; Rojas-Martín, 2015, p. 11).

\section{Relaciones públicas en la comunicación de las administraciones}

Aira, Curto-Gordo y Rom-Rodríguez (2009, p. 203) clasifican las técnicas de comunicación de las administraciones públicas en cuatro áreas:

- instrumentos surgidos por mandato legal;

- instrumentos publicitarios;

- instrumentos vinculados a la actividad periodística, propios del gabinete de prensa;

- instrumentos vinculados a la actividad de las relaciones públicas, que pueden compartir herramientas con los anteriores.

Los mencionados en tercer y cuarto lugar se enmarcan, según la clasificación de PRSA (Public Relations Society of America), en las áreas propias de las relaciones públicas (Wilcox; Cameron; Xifra, 2012; Rojas-Orduña, 2008).

En la definición de relaciones públicas dos elementos sustanciales son el concepto de relación y la figura del stakeholder. Según Cutlip, Center y Broom, las relaciones públicas consisten en: 
"la función directiva que establece y mantiene relaciones mutuamente beneficiosas entre una organización y el público o públicos de quienes dependen su éxito o fracaso" (Cutlip; Center; Broom, 2001, p. 31).

Otros autores también enfatizan la idea de relación desde el punto de vista de la interacción entre la organización y sus stakeholders (Castillo-Esparcia, 2010; Xifra, 2011; Monfort; Villagra; López-Vázquez, 2019).

De esta concepción de las relaciones públicas, se infiere que sus funciones y tareas pueden ser muy diversas, pero todas están orientadas a crear relaciones de diálogo y escucha activa de los públicos, propiciando un clima de confianza mutua. De la etimología de Relaciones Públicas se desprende, así, que el concepto de público es indisociable del de relación (Xifra, 2003), proponiendo algunos teóricos cambiar la denominación de la disciplina "Relaciones públicas" por "Relaciones con los públicos" (Seitel, 2002). Por este motivo, en la gestión de las relaciones públicas un aspecto clave es la identificación de los públicos y su investigación

La transformación digital tiene una importancia capital en la relación entre administraciones y ciudadanía

"para conocer las opiniones, percepciones y expectativas de estos colectivos" (Capriotti; Oliveira; Costa, 2016, p. 28).

Además, la clasificación de los públicos es crucial para la creación de vínculos (Míguez-González, 2010), permitiendo también generar conocimiento y lograr sensibilización u otros objetivos corporativos.

La Teoría situacional de Grunig y Hunt sostiene que

"los públicos surgen cuando la gente reconoce las consecuencias como problemas y se organiza para hacer algo respecto a ellos" (Grunig; Hunt, 2003, p. 26).

En esta línea, Carretón-Ballester también señala que

"la investigación incluye la definición de públicos que intervienen en el problema de relaciones públicas en función de las consecuencias recíprocas de sus comportamientos para lograr el diálogo constructivo" (Carretón-Ballester, 2014, p. 48).

Así, en la gestión de las relaciones públicas es clave la definición de un mapa de públicos. Fernández-Cavia y Huertas-Roig (2009), atendiendo a la clasificación apuntada por Grunig y Hunt (2003), distinguen distintos stakeholders en función de los vínculos que se mantienen con ellos:

- stakeholders con vínculos posibilitadores, como la administración local, accionistas y líderes;

- con vínculos funcionales, como empleados, sindicatos, proveedores, consumidores, clientes y asociados;

- con vínculos normativos, como asociaciones, grupos políticos y colegios profesionales;

- con vínculos difusos, como grupos ecologistas, medios de comunicación y estudiantes.

Otro aspecto clave en la identificación de los stakeholders es la valoración de su importancia ya que, como apuntan Otero-Alvarado y Pulido-Polo (2018), no todos ellos tienen la misma implicación ni posible conflictividad.

En el caso de las administraciones públicas, en la identificación de sus públicos hay que tener en cuenta, por una parte, su mayor capacidad de ejercer presión en la organización y, por otra, la mayor complejidad de su segmentación y variedad (Canel-Crespo, 2007, p. 21). Atendiendo a estos aspectos, existen distintas tipologías. En primer lugar, aludiendo a los actores de la administración electrónica, Martín-Rodrigo ${ }^{1}$ (citado en Gómez-Camarero, 2003, p. 111), identifica los siguientes grupos de interés:

- ciudadanos (Government to citizen);

- empresas (Government to business);

- empleados públicos (Government to employees);

- otras administraciones (Government to government).

Por su parte, Canel-Crespo, amplía los stakeholders de las instituciones estableciendo la siguiente clasificación (2007, p. 235):

- empleados;

- ciudadanos;

- entidades implicadas por las políticas de la institución: sindicatos, colegios profesionales, empresas, patronales, asociaciones internacionales;

- otros poderes del Estado;

- partidos políticos;

- movimientos sociales, grupos de interés y grupos de presión;

- otros gobiernos;

- medios de comunicación;

- líderes de opinión;

- empresas;

- público en general... 


\section{Bidireccionalidad y Relaciones públicas $\mathbf{2 . 0}$}

Al abordar el concepto y gestión de las relaciones públicas en las organizaciones, Grunig y Hunt (2003) son un punto de referencia por su elaboración de los cuatro modelos de relaciones públicas:

- agente de prensa;

- información pública;

- modelo bidireccional asimétrico;

- bidireccional simétrico.

En la actualidad, las relaciones públicas actúan como órgano mediador entre las organizaciones y sus stakeholders (Xifra, 2003). Han evolucionado hacia los modelos de motivación mixta y bidireccional simétrico, favorecido por las nuevas tecnologías de la información y la comunicación (NTIC) que posibilitan la interacción y el diálogo con los públicos.

Esta idea de bidireccionalidad debería guiar la práctica de la comunicación pública, tal como apunta Vañó-Sempere (2015), para apoyar los criterios de transparencia de las instituciones. Además, su adopción según Garnett (2011) puede facilitar que los públicos tengan un rol más activo, convirtiéndose en socios de gobierno. Para ello, son clave las nuevas tecnologías, que permiten una mayor transparencia incrementando las capacidades de los ciudadanos para la participación.

El rol de las NTIC es creciente en todas las esferas de la sociedad y también en la relación entre administraciones y ciudadanos facilitando una gobernanza inteligente (Criado; García-Alonso, 2012; Criado, 2016). La irrupción de internet, sobre todo con la aparición de la web 2.0, ha provocado la necesaria adaptación de las relaciones públicas al contexto digital. Este escenario, definido por Fernández-Dutto (2006) como relaciones públicas 2.0, ha supuesto la utilización de medios que facilitan la interacción con los públicos (Aced-Toledano, 2013; Bruno-Carlos; Paricio-Esteban, 2018).

La web se ha convertido en un instrumento estratégico para los departamentos de relaciones públicas, con objeto de alcanzar a sus públicos clave e interaccionar con ellos (Kirat, 2007). Algunos autores (Capriotti; Pardo-Kuklinski, 2012; Túñez-López, 2015) exponen la importancia de incorporar los rasgos participativos de la web 2.0 en las estrategias organizacionales, con objeto de crear un modelo de simetría interactiva en la comunicación.

En el ámbito público, si bien el proceso de transformación digital se inició más tarde que en el privado (Pérez-Tornero et al., 2018), no se puede obviar la importancia que ha alcanzado en la actualidad en la relación entre administraciones y ciudadanía. Las nuevas tecnologías conllevan la aparición de nuevos instrumentos comunicativos que hacen viable una interacción y una participación más frecuente y proactiva del público (Aznar, 2014; Esteve-Mallent, 2018).

Las NTIC están facilitando el tránsito hacia una administración pública más transparente y accesible mediante el uso de nuevos canales como webs y medios sociales. La utilización de la web 2.0 por las instituciones aporta ventajas en la relación con sus públicos ya que mejora la comunicación de los servicios públicos y fomenta la participación, contribuyendo a crear conciencia social y compromiso ciudadano (Bonsón et al., 2012).

\section{Relaciones públicas en el contexto local}

En la gestión de la comunicación pública es fundamental el papel de las relaciones públicas por su contribución a

"generar valores intangibles como son la confianza o el engagement" (Canel-Crespo; Luoma-aho, 2017, p. 45).

Descendiendo al ámbito local, la comunicación municipal se orienta a la creación de relaciones, apuntadas anteriormente como consustanciales a la función de las relaciones públicas. Puig-Picart entiende la municipalidad como

"relación, como enredo, como comunicación interorganizativa, interactiva con los ciudadanos y para la ciudad" (Puig-Picart, 2003, p. 112).

En esta idea de ciudad relacional, sobresale el público ciudadano junto con el sector asociativo cívico, el sector administrativo líder y el sector empresarial ético. La ciudadanía, como público principal, es cada vez más protagonista en una relación dialógica con sus instituciones, y a partir de la cual los ciudadanos pueden ejercer la monitorización del poder (Alonso-Muñoz; Casero-Ripollés, 2017).

Por su parte, las asociaciones juegan un rol fundamental en la medida en que movilizan, facilitan la consecución de proyectos, y crean opinión pública en la ciudad. El sector administrativo son los públicos internos que trabajan para fomentar la escucha activa de la ciudadanía. Por lo que respecta a las empresas, Puig-Picart (2003) defiende la necesaria implicación de este tipo de organizaciones, ya no sólo desde una perspectiva económica, sino desde una visión ética y de involucración con el proyecto municipal.

Campillo-Alhama (2013) se refiere también a los ciudadanos y movimientos asociativos como stakeholders clave con los que los ayuntamientos se relacionan, incorporando además en el mapa de públicos locales, a los líderes de opinión y los medios de comunicación.

Los medios de comunicación son también un público fundamental de las entidades locales, naciendo los primeros gabinetes municipales como gabinetes de prensa (Almansa-Martínez, 2011; Campillo-Alhama, 2013; Bruno-Carlos; Paricio-Esteban, 2013). Éstos actúan como canal con los ciudadanos aportando notoriedad y credibilidad (Barquero-Ca- 
brero; Pérez-Senac; Barquero-Cabrero, 2010). A estas funciones se une su poder de prescripción y de conformación de la opinión pública, tal y como señalan las principales teorías de los efectos de los medios como las de la agenda setting, la tematización y el encuadre (McCombs; Shaw, 1972; Luhmann, 1978; McCombs, 2006), influyendo la agenda mediática en las agendas institucional y pública. Además, los medios ejercen una función de vigilancia del poder o watchdog (Kovach; Rosenstiel, 2012).

La revolución de las NTIC ha provocado también cambios en la comunicación municipal con el objetivo de contribuir a la gestión de las políticas públicas desde una perspectiva basada en la gobernanza, la transparencia y la participación ciudadana (Campillo-Alhama; Martínez-Sala, 2017). De manera concreta, el sitio web municipal aumenta la transparencia y acerca la institución a la ciudadanía, contribuyendo a una mayor implicación de ésta en los asuntos públicos.

El artículo 69.1 de la Ley 7/1985, de 2 de abril, reguladora de las bases del régimen local (España, 1985) imponía ya a las corporaciones locales el deber de facilitar la más amplia información sobre su actividad y la participación de todos los ciudadanos en la vida local (Campillo-Alhama, 2011). Pero estas obligaciones han aumentado con la legislación de transparencia mencionada anteriormente, que cita a la administración local como sujeto de publicidad activa, obligando a publicar información de ésta en sedes electrónicas o páginas web (arts. 2.1 y 5.4 de la Ley 19/2013, y arts. 2.1 y 7 de la Ley 2/2015 de la Comunidad Valenciana) (España, 2013; 2015).

Estos sitios web en materia de transparencia, desempeñan un rol clave en la interacción entre las instituciones y sus públicos. Jiménez señala que por ello los portales se han convertido en

“la base de la relación entre los ciudadanos, los gobiernos y las administraciones" (Jiménez, 2017, p. 3).

Rodríguez-Breijo, Álvarez-Nobell y Moreno-Sardá (2014) subrayan su papel en la promoción de la participación ciudadana en el ámbito local. En este contexto, como señala Delgado-Morales (2015), el estudio de las webs y portales de transparencia ha adquirido especial protagonismo y organismos externos miden el cumplimiento en materia de transparencia en las corporaciones locales, como el Índice de Transparencia de los Ayuntamientos (ITA) de Transparency International España. Otro ejemplo de estos sistemas de evaluación es el Mapa InfoParticipa, elaborado por el Laboratorio de Periodismo y Comunicación para la Ciudadanía Plural (LPCCP) de la Universitat Autònoma de Barcelona (UAB). Esta metodología ha sido avalada en numerosos estudios (Manfredi-Sánchez, 2017; Molina-Rodríguez-Navas; Simelio-Solà; Corcoy-Rius, 2017; Moreno-Sardà; Molina-Rodríguez-Navas; Simelio-Solà, 2017; Herrero-Gutiérrez et al., 2017; ReboIledo; Zamora-Medina; Rodríguez-Virgili, 2017; Corcoy-Rius, 2018).

\section{Metodología}

Este estudio ofrece respuesta a las siguientes preguntas:

- ¿Qué modelos de gestión de las webs y de los portales de transparencia municipales predominan en los ayuntamientos de la Comunidad Valenciana?

- ¿Cuál de estos modelos se orienta más, desde una perspectiva de las relaciones públicas, a favorecer las relaciones de la entidad municipal con sus principales stakeholders?

Las hipótesis de partida de la investigación son:

H1. Los ayuntamientos utilizan mayoritariamente modelos en la gestión de sus webs y portales de transparencia con un enfoque de relaciones públicas, orientados al diálogo con sus públicos de interés.

H2. El tamaño del municipio influye en el modelo aplicado, encontrando en los municipios más grandes y con más recursos, sitios web y portales con un enfoque de relaciones públicas que propicia una mayor transparencia y participación.

El objetivo general de la investigación se orienta a conocer el uso de la web y el portal de transparencia municipal como herramienta de relaciones públicas, con particular atención a su orientación a la hora de propiciar la interacción con los públicos y fomentar la participación de éstos en la gestión pública.

Los objetivos específicos del estudio son:

1. Identificar los modelos de webs y portales de transparencia más utilizados por los ayuntamientos de la Comunidad Valenciana.

2. Conocer los modelos que potencian más la transparencia y participación en general.

3. Identificar los modelos más aplicados en función del tamaño del municipio.

4. Conocer los modelos que potencian más la transparencia y participación con los principales públicos locales (ciudadanos, medios de comunicación, asociaciones, empresas y órganos de participación).

5. Identificar diferencias en función del tamaño de los municipios, en la gestión de las relaciones públicas con los principales stakeholders locales a través de las webs y portales de transparencia. 
En relación con los objetivos definidos, se ha realizado un análisis de contenido de tipo categorial (Bardin, 1986). El corpus de la investigación está integrado por el $100 \%$ de los ayuntamientos de la Comunidad Valenciana (542 municipios). Estas entidades se han organizado por estratos en función del tamaño de la población.

Por lo que respecta al primero de los objetivos, se ha utilizado la categorización de webs y portales de transparencia (tabla 2) establecida en un estudio piloto centrado en los municipios valencianos de más de 10.000 habitantes ${ }^{2}$, donde los resultados de la investigación permitieron identificar cinco modelos diferenciados (2 diseños propios y 3 tipos de plantilla):

- sitio web independiente específicamente dedicado a transparencia y participación municipal;

- apartado en sitio web municipal dedicado a transparencia y participación;

- portal de transparencia con formato de plantilla ubicada en sede electrónica3;

- plantilla facilitada por el Gobierno de España;

- plantilla elaborada por las diputaciones provinciales.

Tabla 2. Modelos de webs y portales de transparencia

\begin{tabular}{|l|l|}
\hline Modelo 1: Sitio web independiente & $\begin{array}{l}\text { El portal de transparencia es un diseño propio ubicado en un sitio web inde- } \\
\text { pendiente de la web municipal (URL diferente) }\end{array}$ \\
\hline Modelo 2: Apartado en web & $\begin{array}{l}\text { El portal de transparencia es un diseño propio ubicado en un apartado de la } \\
\text { web municipal (al que se accede a través de menú principal o secundario) }\end{array}$ \\
\hline Modelo 3: Plantilla en sede electrónica & El portal de transparencia es una plantilla ubicada en la sede electrónica \\
\hline Modelo 4: Plantilla del Gobierno de España & El portal de transparencia es una plantilla diseñada por el Gobierno del Estado \\
\hline Modelo 5: Plantilla de la Diputación de Valencia & $\begin{array}{l}\text { El portal de transparencia es una plantilla elaborada por las diputaciones } \\
\text { provinciales (sólo identificada la de la Diputación de Valencia) }\end{array}$ \\
\hline Modelo 6: No existe espacio web u otros de transparencia & No hay sección específica de transparencia \\
\hline Otros & Otras fórmulas diferentes de los modelos anteriores \\
\hline
\end{tabular}

Además, en relación con los objetivos 2 y 3, se ha realizado un análisis de contenido basado en la metodología del Mapa InfoParticipa, utilizando sus 52 indicadores, diferenciados en transparencia (38 indicadores) y participación (14 indicadores). http://www.mapainfoparticipa.com/index/home

Respecto a los objetivos 4 y 5, se ha planteado una clasificación de los públicos de los ayuntamientos siguiendo las distintas propuestas examinadas en el marco teórico (Martín-Rodrigo, 2001, cit. en Gómez-Camarero, 2003, p. 111); Puig-Picart, 2003; Canel-Crespo, 2007; Fernández-Cavia; Huertas-Roig, 2009; Almansa-Martínez, 2011; Campillo-Alhama, 2013), identificando como principales stakeholders:

- ciudadanos;

- medios de comunicación;

- asociaciones y entidades ciudadanas (sociedad civil organizada);

- empresas;

- órganos de participación.

A continuación, se ha realizado un análisis de contenido categorial diseñando un libro de códigos a partir de una selección de indicadores del Mapa InfoParticipa. Para ello, se han identificado los indicadores que propician la transparencia y participación con cada uno de los públicos objeto de estudio, involucrando algunos a varios públicos mientras que otros se refieren sólo a uno en particular. En la tabla 3 aparecen reseñados junto con la justificación de su elección en razón de la función realizada con los diferentes stakeholders objeto de estudio.

Finalmente, a través del tratamiento estadístico de los datos se ha analizado la incidencia de los distintos modelos y el tamaño de la población en el cumplimiento de los indicadores específicos de públicos. Para ello, se ha realizado un análisis de regresión, efectuando regresiones lineales donde la variable dependiente ha sido el nivel de cumplimiento y la independiente el modelo de webs y portales de transparencia. Antes de realizar los análisis de regresión se observó una correlación entre las variables tamaño del municipio y los modelos. Por eso se decidió eliminar la variable del tamaño del análisis, para evitar problemas de multicolinealidad. No obstante, para no dejar fuera
La comunicación entendida como relación adquiere un papel fundamental en la interacción de las organizaciones municipales con sus públicos 
Tabla 3. Indicadores específicos de los principales públicos

\begin{tabular}{|c|c|c|c|}
\hline Públicos & \multicolumn{2}{|c|}{ Indicadores específicos } & Justificación \\
\hline \multirow{10}{*}{ Ciudadanos } & \multirow{6}{*}{ Transparencia } & 10 y 11 & Acceso directo a los representantes políticos \\
\hline & & 15,16 y 17 & Participación en la democracia representativa \\
\hline & & 18 & Participación en la democracia representativa y rendición de cuentas \\
\hline & & 21,22 y 25 & Rendición de cuentas \\
\hline & & 28 & Rendición de cuentas e igualdad de acceso a empleo público \\
\hline & & 36 & Rendición de cuentas e igualdad de acceso a ayudas públicas \\
\hline & \multirow{4}{*}{ Participación } & $46,47,48$ y 50 & $\begin{array}{l}\text { Mecanismos institucionales de participación directa en la democracia } \\
\text { representativa }\end{array}$ \\
\hline & & 49 & Mecanismos de la sociedad civil para la participación \\
\hline & & 51 & Rendición de cuentas \\
\hline & & 52 & Participación en la gestión pública \\
\hline \multirow{4}{*}{$\begin{array}{l}\text { Medios de } \\
\text { comunicación }\end{array}$} & \multirow{3}{*}{ Transparencia } & 9 & Función de control del poder político y rendición de cuentas \\
\hline & & 10 y 11 & $\begin{array}{l}\text { Acceso directo para el ejercicio de la función de control del poder } \\
\text { político }\end{array}$ \\
\hline & & $18,21,22$ y 25 & \multirow{2}{*}{ Desarrollo de las labores informativa y de control del poder político } \\
\hline & Participación & $39,40,41$ y 45 & \\
\hline \multirow{4}{*}{ Asociaciones } & Transparencia & $10,11,36$ y 37 & Acceso directo a los representantes políticos \\
\hline & \multirow{3}{*}{ Participación } & 44 & Tener voz y espacio como promotoras de actividades \\
\hline & & $46,47,48$ y 50 & $\begin{array}{l}\text { Mecanismos institucionales de participación directa en la democracia } \\
\text { representativa }\end{array}$ \\
\hline & & 49 & Instrumento de comunicación básico con la ciudadanía \\
\hline \multirow[b]{2}{*}{ Empresas } & Transparencia & $30,31,32,33,34,35$ у 36 & Rendición de cuentas e igualdad de acceso \\
\hline & Participación & 47,48 y 49 & $\begin{array}{l}\text { Mecanismos institucionales de participación directa en la democracia } \\
\text { representativa }\end{array}$ \\
\hline $\begin{array}{l}\text { Órganos de } \\
\text { participación }\end{array}$ & Participación & 46,47 y 48 & Se refieren a este tipo de órganos \\
\hline
\end{tabular}

Fuente: Elaborado a partir del Mapa InfoParticipa

del estudio esta variable, ya que el tamaño del municipio es fundamental en nuestro análisis, se procedió a dividir la muestra en cuatro niveles de estudio, agrupando algunos estratos. Esto permite obtener un modelo explicativo para la muestra global y para las tres submuestras según tamaño (Lago-Peñas, 2008, p. 43). Estos cuatro grupos fueron:

- todas las poblaciones (categoría A);

- poblaciones de más de 20.000 habitantes (categoría B);

- poblaciones de menos de 20.000 habitantes (categoría D);

- poblaciones de entre 20.000 y 50.000 habitantes (categoría C).

La recogida de datos y el análisis realizado se han llevado a cabo entre los meses de julio de 2018 y julio de 2019. Para el tratamiento de los datos se han utilizado Microsoft Office Excel e IBM SPSS Statistics 21.

\section{Resultados}

\subsection{Modelos de web y portal de transparencia. Cumplimiento de indicadores y diferencias por tamaño del municipio}

En primer lugar, en relación con los 52 indicadores del Mapa InfoParticipa, se observa que el 92,25\% de los ayuntamientos de la Comunidad Valenciana no cumple en sus webs y portales de transparencia el $50 \%$ de los indicadores de transparencia y participación. Sólo el 7,75\% tiene un cumplimiento igual o mayor al $50 \%$. Además, el $67,34 \%$ de los municipios registra niveles de cumplimiento inferiores al $25 \%$ y sólo el $1,29 \%$ de los ayuntamientos cumple más del $75 \%$ de los indicadores.

En segundo lugar, tomando como base estos datos generales de cumplimiento, se presentan los resultados sobre el uso de modelos y sus niveles de cumplimiento de indicadores del Mapa InfoParticipa.

Respecto al uso de modelos de web o portales de transparencia, la fórmula utilizada mayoritariamente es la plantilla (73\% de los ayuntamientos) frente a los diseños propios. Concretamente, el $57 \%$ de los ayuntamientos emplea la plantilla en sede electrónica (modelo 3); un 9\% la plantilla de la Diputación provincial (modelo 5) y un 7\% la plantilla del Gobierno de España (modelo 4). En el caso de los modelos propios, el apartado en sitio web (modelo 2) es la opción más seguida, con un $11 \%$, siendo más baja la presencia de la web independiente (modelo 1), con un $5 \%$. 
El cumplimiento de los indicadores por modelos se muestra en la tabla 4, donde se observa que el modelo más utilizado, plantilla en sede electrónica, es el que registra peores niveles de cumplimiento. El 74,75\% de los ayuntamientos que lo utiliza no llega al $25 \%$ de cumplimiento. Por el contrario, en los modelos propios (web independiente y apartado en web) se han hallado los mejores niveles de cumplimiento (75\% de los indicadores en transparencia y participación) si bien, esta cifra sólo se ha encontrado en 6 municipios ( 3 de cada modelo).

Tabla 4. Cumplimiento general de indicadores por modelos

\begin{tabular}{|c|c|c|c|c|c|c|c|c|}
\hline Cumplimiento & Modelo 1 & Modelo 2 & Modelo 3 & Modelo 4 & Modelo 5 & Modelo 6 & Otros & Error \\
\hline $75-100 \%$ & 3 & 3 & 0 & 0 & 1 & 0 & 0 & 0 \\
\hline $50-74 \%$ & 7 & 15 & 6 & 4 & 3 & 0 & 0 & 0 \\
\hline $25-49 \%$ & 9 & 19 & 72 & 12 & 18 & 2 & 2 & 1 \\
\hline $0-24 \%$ & 10 & 24 & 231 & 19 & 28 & 35 & 10 & 8 \\
\hline Total & 29 & 61 & 309 & 35 & 50 & 37 & 12 & 9 \\
\hline
\end{tabular}

Atendiendo a la distinción del Mapa InfoParticipa entre indicadores de transparencia (38) y participación (14), se puede destacar que en la mayoría de los modelos se observa un cumplimiento más elevado en participación que en transparencia, con la excepción de la web independiente. Sobresalen en cumplimiento la web independiente y el apartado en sitio web, con niveles muy cercanos en transparencia y participación.

Respecto a los indicadores de transparencia del Mapa InfoParticipa la media más baja sigue registrándola la plantilla en sede electrónica (16,74\%) y la más alta de cumplimiento se obtiene en los diseños propios: 40,56\% en los ayuntamientos con web independiente y $31,71 \%$ en los que tienen apartados específicos en la web. Le siguen las plantillas de la Diputación (22,79\%) y del Gobierno de España (21,88\%). En el análisis de la participación, la media superior se alcanza también en los diseños propios (37,44\% en el modelo 1 y 34,31\% en el modelo 2 ), seguidos de las plantillas del Gobierno de España (28,98\%) y de la Diputación (26,29\%). En la plantilla en sede electrónica el nivel de cumplimiento es también el más bajo $(24,60 \%)$.

En la tabla 5 se muestra la relación entre los modelos utilizados y el tamaño del municipio. En el estrato I (más de 100.000 habitantes) sólo se utilizan los modelos 1 y 2 . En el estrato II (50.001-100.000 habitantes), el más usado es el modelo 2 (54,55\%), y en el estrato III (20.001-50.000 habitantes) el modelo 2 concentra el mayor número de ayuntamientos, que representa el 30,61\%. A partir del estrato IV (menos de 20.000 habitantes), hasta el IX, predomina el modelo 3 (62,97\%). Por consiguiente, los municipios con más población (a partir de 20.000 habitantes) son los que utilizan principalmente modelos propios, mientras que los de menos de 20.000 optan más por el uso de plantillas, especialmente la de sede electrónica.

Tabla 5. Utilización de los modelos por tamaño del municipio

\begin{tabular}{|c|c|c|c|c|c|c|c|c|}
\hline Población & Modelo 1 & Modelo 2 & Modelo 3 & Modelo 4 & Modelo 5 & Modelo 6 & Otros & Error \\
\hline$>100.000$ & 2 & 2 & 0 & 0 & 0 & 0 & 0 & 0 \\
\hline $50.001-100.000$ & 2 & 6 & 1 & 2 & 0 & 0 & 0 & 0 \\
\hline $20.001-50.000$ & 9 & 15 & 7 & 8 & 6 & 2 & 1 & 1 \\
\hline $10.001-20.000$ & 4 & 4 & 13 & 4 & 8 & 0 & 0 & 0 \\
\hline $5.001-10.000$ & 2 & 11 & 36 & 2 & 5 & 1 & 1 & 0 \\
\hline $1.001-5.000$ & 7 & 13 & 102 & 8 & 20 & 6 & 3 & 4 \\
\hline $501-1.000$ & 3 & 5 & 41 & 5 & 5 & 12 & 2 & 3 \\
\hline $101-500$ & 0 & 5 & 88 & 6 & 6 & 15 & 3 & 1 \\
\hline$<100$ & 0 & 0 & 21 & 0 & 0 & 1 & 2 & 0 \\
\hline Total & 29 & 61 & 309 & 35 & 50 & 37 & 12 & 9 \\
\hline
\end{tabular}

Por último, relacionando los modelos por tamaño del municipio con la transparencia y participación, la web independiente (predominante junto con el modelo 2 en los ayuntamientos de más de 100.000 habitantes) es la que obtiene la media más alta de cumplimiento de indicadores del Mapa InfoParticipa. En los estratos II y III (entre 20.000 y 100.000) el modelo mayoritario (apartado en sitio web) es el que registra un cumplimiento del 50 al $74 \%$ en más casos.

Los niveles de cumplimiento bajan en el resto de los modelos, hallando excepciones en la plantilla del Gobierno de España (con 4 casos de cumplimientos superiores al 50\% en estratos II, III y V) y en la de la Diputación (con 1 municipio con un cumplimiento de más del 75\%). 
En el caso de la sede electrónica, siendo el modelo utilizado por más municipios, registra los menores niveles de cumplimiento (por debajo del 50\%). Este dato puede estar también relacionado con su aplicación mayoritaria por municipios con menor población y menos recursos (por debajo de los 5.000 habitantes).

\subsection{Públicos locales. Cumplimiento de indicadores y diferencias por tamaño del municipio}

El gráfico 1 recoge los niveles de cumplimiento de los indicadores del Mapa InfoParticipa definidos para los principales públicos locales establecidos en la investigación: ciudadanos, medios de comunicación, asociaciones, empresas y órganos de participación.

En general, la web y los portales de transparencia no favorecen la relación con los stakeholders analizados al registrarse niveles de cumplimiento inferiores al 50\% en todos los públicos (la mayoría no llega al 25\%). En particular, el $89,3 \%$ de los ayuntamientos cumple menos del $50 \%$ de los indicadores relativos a los ciudadanos y el $89,12 \%$ de los municipios también registra cumplimientos inferiores al $50 \%$ en el caso de las asociaciones. Los niveles de cumplimiento más bajos se registran en los órganos de participación (95,39\%), los medios $(95,20 \%)$ y las empresas $(91,14 \%)$. Así, el cumplimiento de indicadores específicos de públicos superior al 50\% se limita en el caso de las asociaciones al 10,89\% de los ayuntamientos; en el público ciudadanos, 10,71\%; empresas, 8,86\%; medios, 4,8\%, y órganos de participación, 4,61\%.

Es reseñable que los medios de comunicación se sitúan entre los públicos con menor nivel de cumplimento en sus indicadores junto con los órganos de participación; si bien, en estos últimos es paradójico hallar más municipios (aunque sólo son el $2 \%$ de la muestra) con un nivel de cumplimiento superior al $75 \%$.

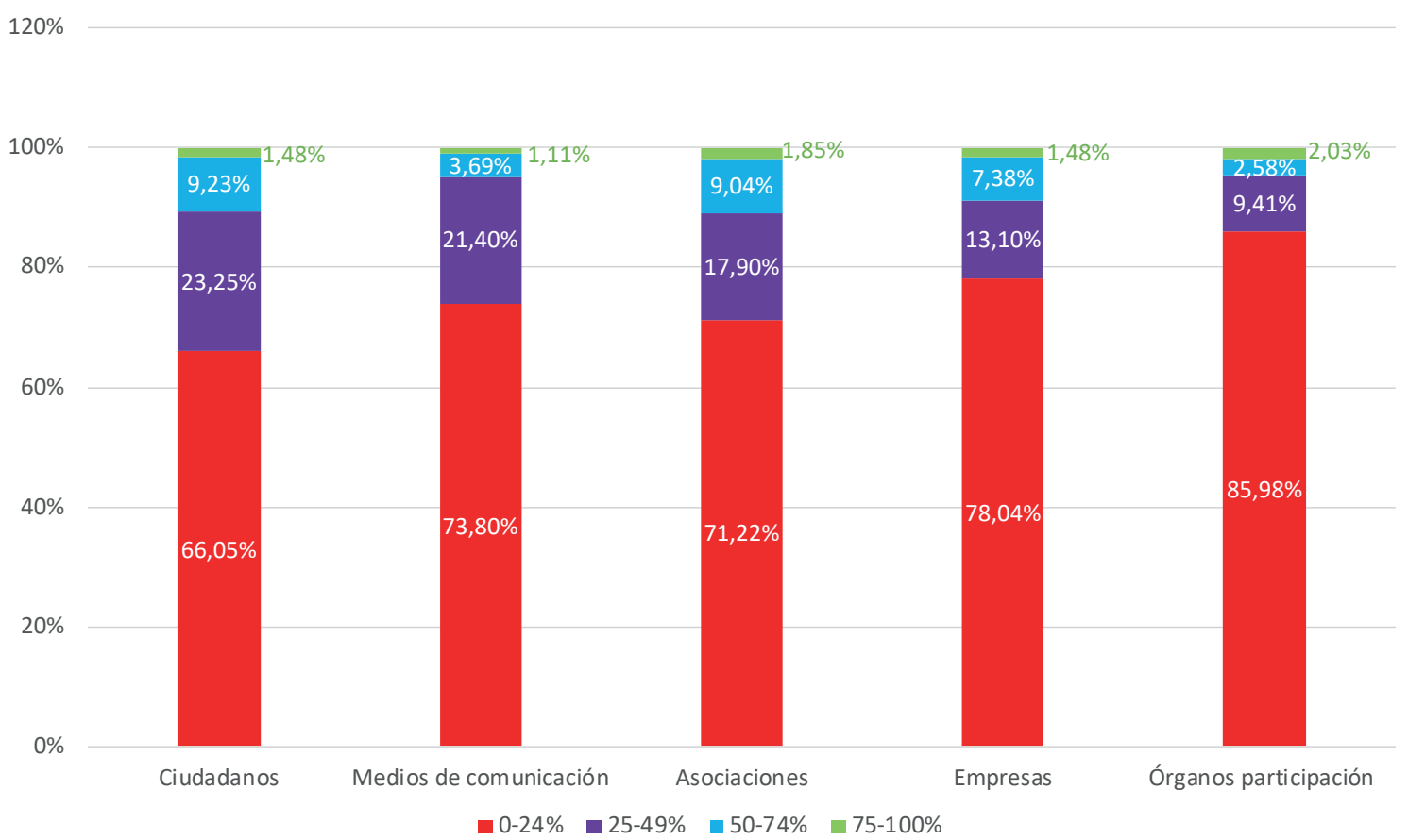

Gráfico 1. Cumplimiento de indicadores específicos de públicos

Atendiendo al modelo de web y portal de transparencia utilizado, los resultados de cumplimiento de indicadores específicos de públicos coinciden con los datos de cumplimiento general. En relación con los ciudadanos (tabla 6), el cumplimiento por encima del $75 \%$ se corresponde principalmente con la utilización de los dos primeros modelos, si bien la cifra de municipios en global es baja (un $13,79 \%$ de los ayuntamientos con web independiente y un $4,92 \%$ con apartado en web). Dichos modelos presentan también el mayor porcentaje de aprobados (34,48\% en el modelo 1 y $32,79 \%$ en el 2). Entre los municipios que tienen sección especifica de transparencia, el mayor número de casos de un cumplimiento inferior al 25 \% se sitúa en los ayuntamientos que usan la sede electrónica. Estos resultados se replican en el resto de los públicos con porcentajes similares en relación con los modelos utilizados por los municipios.

Tabla 6. Cumplimiento de indicadores específicos del público ciudadanos por modelos

\begin{tabular}{|c|c|c|c|c|c|c|}
\hline Cumplimiento & $\begin{array}{c}\text { Modelo } 1 \\
\%\end{array}$ & $\begin{array}{c}\text { Modelo } 2 \\
\%\end{array}$ & $\begin{array}{c}\text { Modelo } 3 \\
\%\end{array}$ & $\begin{array}{c}\text { Modelo } 4 \\
\%\end{array}$ & $\begin{array}{c}\text { Modelo } 5 \\
\%\end{array}$ & $\begin{array}{c}\text { Modelo } 6 \\
\%\end{array}$ \\
\hline $75-100 \%$ & 13,79 & 4,92 & 0,00 & 0,00 & 2,00 & 0,00 \\
\hline $50-74 \%$ & 20,69 & 27,87 & 5,83 & 14,29 & 6,00 & 0,00 \\
\hline $25-49 \%$ & 27,59 & 22,95 & 24,92 & 25,71 & 26,00 & 5,41 \\
\hline $0-24 \%$ & 37,93 & 44,26 & 69,26 & 60,00 & 66,00 & 94,59 \\
\hline
\end{tabular}


Respecto a las asociaciones, los niveles de cumplimiento mejoran ligeramente en algunos modelos. Los municipios que utilizan los diseños propios (modelos 1 y 2 ) son los que cumplen más indicadores relativos a este stakeholder $(37,93 \%$ de los que usan el modelo 1 y el $34,42 \%$ en el modelo 2). Las cifras más bajas se obtienen con el modelo 3 (el 95,8\% se sitúa por debajo del cumplimiento del 50\%).

Particularmente, los peores resultados en relación con todos los modelos usados se hallan en los medios de comunicación y órganos de participación. En éstos y particularmente con el modelo 3, se observan los niveles inferiores de cumplimiento (el 98,4\% de los municipios cumple menos del 50\% de indicadores en el caso de los medios, y el 99,36\%, en el caso de los órganos de participación). Con los modelos 1 y 2 (web independiente y apartado en sitio web), que registraban en otros públicos los mejores resultados, en estos dos stakeholders también se reducen (para los medios, sólo se observa un cumplimiento superior al $50 \%$ en el $31,03 \%$ de ayuntamientos con el modelo 1 y en el 13,11\% con el modelo 2, y para los órganos participativos, en el $24,14 \%$ con el modelo 1 y en el $18,03 \%$ con el modelo 2 ).

Según el tamaño del municipio se observa que los ayuntamientos con más población (más de 50.000 habitantes) realizan un uso de la web y portal de transparencia que propicia la relación con los públicos locales objeto de estudio. Los que tienen más de 100.000 habitantes registran cumplimientos en todos los públicos superiores al $75 \%$. Le siguen los municipios del estrato II (50.000-100.000 habitantes), que mayoritariamente presentan resultados superiores al $50 \%$ con todos los stakeholders analizados, salvo con los órganos de participación (sólo el 45,45\%).

Por el contrario, en los municipios de menor tamaño la web y portal de transparencia no se orienta, con un enfoque de relaciones públicas, para propiciar la transparencia y participación de los stakeholders locales. A partir del estrato VI (menos de 5.000 habitantes) la mayoría de ayuntamientos tiene un cumplimiento de indicadores del Mapa InfoParticipa inferior al $25 \%$ en todos los públicos.

Cabe apuntar que para este nivel de cumplimiento (entre el 0 y el $24 \%$ ), la línea de tendencia muestra un incremento constante a medida que el tamaño de la población disminuye, tal y como se observa en el gráfico 2 para los órganos de participación.

Es reseñable que los municipios con menos de 50.000 habitantes (estratos III a IX), que representan el $97,23 \%$ de la muestra, registran mayoritariamente en todos los públicos cumplimientos inferiores al 50\%. De todos ellos, es más significativo el caso de los municipios del estrato III (20.000-50.000 habitantes), con un tamaño medio grande y con un cumplimiento en los diferentes públicos inferior al 50\%. El público con mejores resultados de cumplimiento es la ciudadanía (46,93\% de ayuntamientos por encima del 50\%) y con peores resultados los medios de comunicación (16,33\%).
180

160

140

120

100

60

40

20

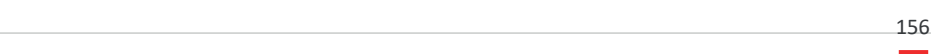

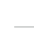

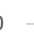

$80-$

60

40

20
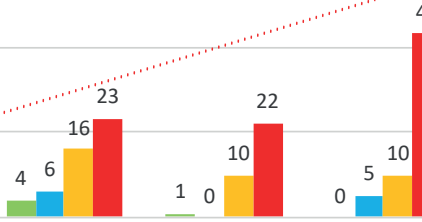

43

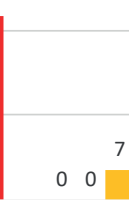

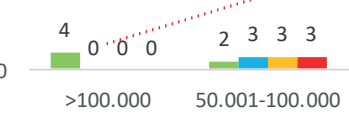

$\mathbf{7 5 - 1 0 0 \%}$

5.001-10.000

1.001-5.000

$0 \quad 0^{3}$

$\begin{array}{lll}0 & 0 & 0\end{array}$

501-1.000

101-500

$<100$

Gráfico 2. Cumplimiento de indicadores específicos del público órganos de participación por tamaño del municipio 


\subsection{Resultados del análisis de regresión para los públicos locales. Modelos de webs y portales y tamaño del municipio}

En primer lugar, la tabla 7 muestra el análisis para el público ciudadanos. En este caso, si no tenemos en cuenta el tamaño de la población (categoría A), los modelos web independiente y apartado en web (que como se ha apuntado anteriormente, son los que utilizan mayoritariamente los municipios de más de 50.000 habitantes) son los únicos que tienen una significatividad del $99 \%$ y un efecto positivo sobre el cumplimiento de indicadores. En poblaciones de más de 20.000 habitantes ningún modelo es significativo a la hora de determinar el cumplimiento de indicadores. Estos resultados serán comunes a los obtenidos para el resto de los públicos. Pero para poblaciones pequeñas (categoría D) los resultados cambian y, aunque la web independiente sigue siendo un modelo significativo (significatividad del 95\%) a la hora de cumplir indicadores, dejan de serlo el apartado propio en web y pasa a tener significatividad la plantilla de la Diputación (significatividad del 95\%).

Tabla 7. Análisis de regresión lineal (ordinary least squares, OLS) de nivel de cumplimiento para ciudadanos

\begin{tabular}{|c|c|c|c|c|c|c|c|c|c|}
\hline & & \multicolumn{2}{|c|}{$\begin{array}{l}\text { Categoría A } \\
\text { Todos }\end{array}$} & \multicolumn{2}{|c|}{$\begin{array}{l}\text { Categoría B } \\
\text { Más } 20.000\end{array}$} & \multicolumn{2}{|c|}{$\begin{array}{c}\text { Categoría C } \\
20.001-50.000\end{array}$} & \multicolumn{2}{|c|}{$\begin{array}{c}\text { Categoría D } \\
\text { Menos o igual } 20.000\end{array}$} \\
\hline & & B & $p$ & B & $p$ & B & $p$ & B & $p$ \\
\hline Constante & & & * & & $* *$ & & $* *$ & & * \\
\hline \multirow{7}{*}{ Modelo } & Web independiente & 0,302 & $* *$ & 0,163 & ns & 0,097 & ns & 0,159 & * \\
\hline & Apartado en web & 0,324 & $* *$ & 0,167 & ns & 0,010 & ns & 0,157 & ns \\
\hline & Sede electrónica & 0,153 & ns & $-0,057$ & ns & $-0,113$ & ns & 0,322 & ns \\
\hline & Gobierno/Estado & 0,126 & ns & $-0,161$ & ns & $-0,239$ & ns & 0,105 & ns \\
\hline & Diputación & 0,119 & ns & $-0,269$ & ns & $-0,354$ & ns & 0,220 & * \\
\hline & No existe portal & $-0,112$ & ns & $-0,265$ & ns & $-0,353$ & ns & $-0,079$ & ns \\
\hline & Otros & 0,126 & ns & 0,163 & ns & 0,097 & ns & 0,159 & ns \\
\hline \multicolumn{2}{|c|}{ Adjusted R square } & \multicolumn{2}{|c|}{$13,8 \%$} & \multicolumn{2}{|c|}{$18,5 \%$} & \multicolumn{2}{|c|}{$16,8 \%$} & \multicolumn{2}{|c|}{$6,4 \%$} \\
\hline
\end{tabular}

Para el público medios de comunicación, los resultados son similares a los de los ciudadanos, excepto en poblaciones menores de 20.000 habitantes, donde únicamente es significativo el modelo de web independiente (con una significatividad sólo del 95\%). Así, ni el modelo de apartado propio en web ni el de plantilla de la Diputación tendrán significatividad. Los resultados para las asociaciones son los mismos que para los medios.

En el caso del público empresas, en poblaciones pequeñas el modelo web independiente y la plantilla de la Diputación presentan una significación del 99\%, siendo además significativo el modelo de plantilla del Gobierno de España (sólo con significación del 95\%).

Tabla 8. Análisis de regresión lineal (ordinary least squares, OLS) de nivel de cumplimiento para órganos de participación

\begin{tabular}{|c|c|c|c|c|c|c|c|c|c|}
\hline & & \multicolumn{2}{|c|}{$\begin{array}{c}\text { Categoría A } \\
\text { Todos }\end{array}$} & \multicolumn{2}{|c|}{$\begin{array}{l}\text { Categoría B } \\
\text { Más } 20.000\end{array}$} & \multicolumn{2}{|c|}{$\begin{array}{c}\text { Categoría C } \\
20.001-50.000\end{array}$} & \multicolumn{2}{|c|}{$\begin{array}{c}\text { Categoría D } \\
\text { Menos o igual } 20.000\end{array}$} \\
\hline & & B & $p$ & B & $p$ & B & $p$ & B & $p$ \\
\hline Constante & & & ns & & ns & & * & & ns \\
\hline \multirow{7}{*}{ Modelo } & Web independiente & 2,768 & $* *$ & $-0,201$ & ns & $-0,230$ & ns & 1,688 & ns \\
\hline & Apartado en web & 2,161 & * & $-0,271$ & ns & $-0,524$ & ns & 1,384 & ns \\
\hline & Sede electrónica & $-0,791$ & ns & $-0,462$ & ns & $-0,588$ & ns & 0,542 & ns \\
\hline & Gobierno/Estado & 0,880 & ns & $-0,439$ & ns & $-0,544$ & ns & 2,015 & ns \\
\hline & Diputación & $-0,420$ & ns & $-0,452$ & ns & $-0,585$ & ns & 0,864 & * \\
\hline & No existe portal & $-0,837$ & ns & $-0,243$ & ns & $-0,318$ & ns & 0,213 & ns \\
\hline & Otros & 2,768 & ns & $-0,201$ & ns & $-0,230$ & ns & 1,688 & ns \\
\hline \multicolumn{2}{|c|}{ Adjusted $R$ square } & \multicolumn{2}{|c|}{$14,9 \%$} & \multicolumn{2}{|c|}{$9,0 \%$} & \multicolumn{2}{|c|}{$7,1 \%$} & \multicolumn{2}{|c|}{$2,4 \%$} \\
\hline
\end{tabular}


Por último, para el público órganos de participación (tabla 8) se obtienen unos resultados que difieren de los anteriores para poblaciones pequeñas (categoría D). Llama la atención que el modelo web independiente no resulta significativo y el único modelo significativo es el de la plantilla de la Diputación (sólo con una significación del 95\%).

\section{Discusión y conclusiones}

La investigación se planteaba analizar el uso de las webs y los portales de transparencia en los ayuntamientos de la Comunidad Valenciana para conocer si, más allá de dar respuesta a las obligaciones legales (Beltrán-Orenes; Martínez-Pastor, 2017), son tratados como una oportunidad para las relaciones públicas con los stakeholders principales de la administración local.

Con relación al primer objetivo, conocer los modelos de webs y portales de transparencia utilizados por los ayuntamientos de la Comunidad Valenciana, se observa una amplia variedad de modelos. Predomina el uso de portales con plantillas elaboradas por otros organismos frente a los diseños propios, siendo la fórmula más utilizada la sede electrónica (modelo 3). Entre el resto de las plantillas, el modelo de la Diputación Provincial (modelo 5) está presente en más municipios que la plantilla del Gobierno de España (modelo 4).

La aplicación del Mapa InfoParticipa en el análisis de los modelos de web y portal ha permitido conocer las fórmulas que favorecen la transparencia y la participación local (objetivo 2 del trabajo). Del estudio se infiere que la información que proporcionan los ayuntamientos en sus web y portales es mayoritariamente insuficiente (predominan los cumplimientos inferiores al 50\%). Este hecho limita su rol como fuentes informativas garantes de la transparencia en orden a la rendición de cuentas a los administrados, así como la posibilidad de procurar formas de participación, coincidiendo con estudios previos como el de Moreno-Sardá, Molina-Rodríguez-Navas y Simelio-Solà (2017).

Destaca el bajo uso de fórmulas propias como el portal de transparencia en web independiente (modelo 1) que junto con el modelo 2, registran más casos con niveles mayores de cumplimiento de indicadores, tanto en transparencia como en participación, en línea con la investigación de Rebolledo; Zamora-Medina; Rodríguez-Virgili (2017).

En relación con el objetivo 3, conocer los modelos aplicados en función del tamaño del municipio, se concluye en primer lugar que no existen modelos exclusivos asociados a uno de los estratos establecidos, si bien se ha detectado una presencia mayoritaria de los modelos propios en los municipios con más población, mientras que en los municipios medianos y pequeños predominan las plantillas. Por consiguiente, se puede concluir que el tamaño condiciona el modelo priorizado por los ayuntamientos, detectando la existencia de una brecha entre municipios grandes de más de 20.000 habitantes y el resto.

Son los de mayor población (a partir de 100.000 habitantes), entre los que se encuentran las tres capitales de provincia, los que realizan una mayor apuesta por los diseños propios (modelo de web independiente y apartado propio en el sitio web municipal) con mayores índices de cumplimiento de indicadores de transparencia y participación. Frente a estas fórmulas, los municipios por debajo de 20.000 habitantes, que constituyen la mayoría de la muestra, optan principalmente por plantillas, sobresaliendo la sede electrónica que es el modelo que registra menor cumplimiento. Estos datos refuerzan las conclusiones de trabajos anteriores (Moreno-Sardá et al., 2015) que también encontraban diferencias en los niveles de transparencia y participación propiciados a través de las web y portales en función del tamaño del municipio.

El aspecto central de la investigación ha sido conocer los modelos de web y portales de transparencia que favorecen más la relación con los principales públicos de los ayuntamientos (objetivo 4). Se concluye que estos canales no se contemplan en general como medios para potenciar el diálogo con ciudadanos, medios de comunicación, asociaciones, empresas y órganos de participación, a tenor del bajo cumplimiento de los indicadores definidos para estos públicos en la mayoría de los municipios.

Por públicos, los ciudadanos y asociaciones, considerados prioritarios en el municipio entendido como ciudad relacional (Puig-Picart, 2003), son los que obtienen mejores resultados aun registrándose niveles bajos de cumplimiento de indicadores.

Atendiendo a los modelos, los diseños propios (web independiente y apartado en web municipal), siendo los menos utilizados, propician un mejor diálogo con ciudadanos y asociaciones. Por el contrario, el modelo más utilizado, sede electrónica, es el menos transparente y participativo para los ciudadanos individuales y organizados.

Es reseñable que frente al papel central otorgado a los medios en las administraciones locales (Castillo-Esparcia; Almansa-Martínez, 2002), sea uno de los públicos en los que se observa un menor cumplimiento de indicadores, no encontrando un modelo que propicie las relaciones con los medios. De ello se infiere la poca orientación de todas las fórmulas de webs y portales de transparencia utilizadas por los ayuntamientos de la Comunidad Valenciana hacia la relación con este stakeholder. 
Por lo que respecta al objetivo 5 del trabajo, se concluye que el tamaño influye en la orientación de las webs y portales de transparencia para la generación de relaciones con los públicos municipales. A medida que desciende la población, se observa un menor cumplimiento de indicadores en todos los públicos, mientras que los municipios de mayor tamaño presentan cumplimientos por encima del 50\%, sobresaliendo los de más de 100.000 habitantes (sólo 4 ayuntamientos) en todos los stakeholders menos los órganos de participación.

En el análisis de las regresiones lineales para cada uno de los públicos, se ha observado que la web independiente (modelo 1) y el apartado en sitio web (modelo 2) son significativos, en particular en poblaciones grandes. Además, el primer modelo también lo es en poblaciones pequeñas con diferentes públicos, aunque su uso es bajo. En estos municipios también es significativa la plantilla de la Diputación (sobre todo en el caso de ciudadanos, medios, asociaciones y empresas). De estos resultados se infiere que los modelos de web independiente y también la plantilla de la Diputación, en poblaciones más pequeñas, son fórmulas que determinan que haya un mayor cumplimiento de indicadores en casi todos los públicos, siendo el buen uso de la última una oportunidad para favorecer las relaciones con los públicos en estos ayuntamientos con menos población y recursos para destinar a la elaboración de diseños propios.

Por todo ello se concluye una influencia del tamaño del municipio y el tipo de modelo elegido en la relación con los principales stakeholders locales a través de las webs y portales de transparencia municipales.

A partir de lo expuesto, queda refutada la hipótesis I en la que se presuponía que los ayuntamientos utilizan modelos en la gestión de webs y portales de transparencia orientados al diálogo con sus públicos de interés, ya que no es así en la mayoría de las entidades municipales de la Comunidad Valenciana, al emplear principalmente la plantilla en sede electrónica, con los niveles más bajos de cumplimiento de indicadores. Además es minoritario el uso de diseños propios (webs independientes y espacios en las webs municipales) que, desde una perspectiva de las relaciones públicas, se ha verificado que favorecen más la interacción con los stakeholders locales.

Por otra parte, se valida la hipótesis II, al probar el estudio que el tamaño del municipio influye en el modelo aplicado, siendo los ayuntamientos más grandes los que optan por los modelos de web independiente y espacio en sitio web, que propician una mayor transparencia y participación de los públicos.

Esta investigación se alinea con el trabajo de Vázquez-Gestal y Fernández-Souto (2014) que apuntaban que queda mucho camino por andar para los profesionales de las relaciones públicas en administraciones locales. Así, a pesar de que la práctica totalidad de los ayuntamientos ha realizado el esfuerzo de contar con webs y portales de transparencia -disponiendo de una plataforma interactiva con un gran potencial para la generación de relaciones con los stakeholders- falta un enfoque de relaciones públicas que mejore su utilización en términos de transparencia y participación ciudadana.

Una de las limitaciones del trabajo es la falta de conocimiento de los condicionantes de la gestión de la comunicación municipal, en los distintos perfiles de municipios analizados, que pueden influir en las diferencias observadas en el uso de modelos propios o plantillas y en el cumplimiento de indicadores, tanto general como por públicos. Ello podría motivar investigaciones posteriores con metodologías de tipo cualitativo donde se pudiera conocer la percepción de los responsables de webs y portales de transparencia municipales al respecto.

Por último, y a partir del estudio realizado, se puede concluir que dadas las carencias observadas en las webs y portales de transparencia de la mayoría de los municipios de la Comunidad Valenciana puede parecer que muchos ayuntamientos las han implantado meramente para dar respuesta a la exigencia legal, desaprovechando su potencial para generar un diálogo constructivo con los stakeholders.

\section{Notas}

1. Tomás Martín Rodrigo: "Proyectos vertebradores del Ministerio de Administraciones Públicas en el ámbito de la administración electrónica". Ponencia pronunciada en el Seminario La nueva Administración del Estado. e-Administración: Conectando con los ciudadanos, celebrado en el Instituto Nacional de Administraciones Públicas (Madrid, 2001).

2. Presentado en el III Congreso internacional de calidad democrática, buen gobierno y lucha contra la corrupción (Valencia, 2019).

3. En el contexto de la Administración pública, sede electrónica es la denominación que las propias administraciones han dado a un espacio específico en sus webs (a veces con una url distinta), que tiene que ver con la implantación de la administración electrónica (ey 11/2007, de 22 de junio, de acceso electrónico de los ciudadanos a los Servicios Públicos) y está destinado a la realización de trámites online (aunque puede tener otros contenidos). 


\section{Bibliografía}

Aced-Toledano, Cristina (2013). Relaciones públicas 2.0. Cómo gestionar la comunicación corporativa en el entorno digital. Barcelona: UOC. ISBN: 9788490292495

http://openaccess.uoc.edu/webapps/o2/bitstream/10609/111306/6/9788490299951.pdf

Aira, Toni; Curto-Gordo, Víctor; Rom-Rodríguez, Josep (2009). Comunicació política i d'institucions públiques. Barcelona: Editorial UOC. ISBN: 9788497888103

Almansa-Martínez, Ana (2011). Del gabinete de prensa al gabinete de comunicación: La dirección de comunicación en la actualidad. Zamora: Comunicación Social. ISBN: 9788492860906

Alonso-Muñoz, Laura; Casero-Ripollés, Andreu (2017). “Transparencia y monitorización en el entorno digital. Hacia una tipología de las plataformas impulsadas por la ciudadanía". Revista latina de comunicación social, n. 72, pp. 1351-1366. https://doi.org/10.4185/RLCS-2017-1223

Aznar, Hugo (2014). "De masas a públicos: ¿cambios hacia una democracia deliberativa?”. En: Aznar, Hugo; PérezLlavador, Jordi (eds.). De la democracia de masas a la democracia deliberativa. Barcelona: Ariel, pp. 97-126. ISBN: 978 8434418653

Bardin, Laurence (1986). Análisis de contenido. Madrid: Akal. ISBN: 9788476000936

Barquero-Cabrero, José-Daniel; Pérez-Senac, Román; Barquero-Cabrero, Mario (2010). Dirección estratégica de relaciones públicas. Barcelona: Profit. ISBN: 9788492956036

Beltrán-Orenes, Pilar; Martínez-Pastor, Esther (2017). “Organización de la información y sujetos obligados en el Portal de la transparencia de España". El profesional de la información, v. 26, n. 5, pp. 983-994.

https://doi.org/10.3145/epi.2017.sep.19

Bonsón, Enrique; Torres, Lourdes; Royo, Sonia; Flores, Francisco (2012). “Local e-government 2.0: Social media and corporate transparency in municipalities". Government information quarterly, v. 29, n. 2, pp. 123-132.

https://doi.org/10.1016/j.giq.2011.10.001

Bruno-Carlos, Teresa; Paricio-Esteban, Pilar (2013). "Relaciones públicas y gabinetes de comunicación municipales. Análisis de la gestión y evaluación de las relaciones con los medios de los gabinetes de comunicación municipales de la comarca de l'Horta de Valencia". Revista internacional de relaciones públicas, v. 3, n. 5, pp. 149-170.

https://doi.org/10.5783/RIRP-5-2013-09-149-170

Bruno-Carlos, Teresa; Paricio-Esteban, Pilar (2018). “Transparencia y participación ciudadana en las webs municipales: estudio de los ayuntamientos de Valencia, Castellón y Alicante". En: Aznar, Hugo; Pérez-Gabaldón, Marta; Alonso-Romero, Elvira; Edo-Ibáñez, Aurora (eds.). El derecho de acceso a los medios de comunicación. II. Participación ciudadana y de la sociedad civil. Valencia: Tirant, pp. 109-140. ISBN: 9788417508449

Campillo-Alhama, Concepción (2011). "La dirección de comunicación municipal: estructuras, procesos y entidades declarantes". Revista internacional de relaciones públicas, v. 1, n. 2, pp. 41-60.

https://doi.org/10.5783/RIRP-2-2011-03-41-60

Campillo-Alhama, Concepción (2013). "La administración municipal relacional y participativa. Cómo construir la identidad de las ciudades desde una perspectiva de comunicación neopública". Revista de comunicación de la Seeci, v. 17, n. 30, pp. 74-93.

https://doi.org/10.15198/seeci.2013.30.74-93

Campillo-Alhama, Concepción; Martínez-Sala, Alba-María (2017). “Comunicación integrada 2.0 en la administración municipal". El profesional de la información, v. 26, n. 3, pp. 507-515.

https://doi.org/10.3145/epi.2017.may.17

Canel-Crespo, María-José (2007). Comunicación de las instituciones públicas. Madrid: Tecnos. ISBN: 9788430946556

Canel-Crespo, María-José (2018). La comunicación de la administración pública. Para gobernar con la sociedad. México: Fondo de Cultura Económica. ISBN: 9788437508092

Canel-Crespo, María-José; Luoma-aho, Vilma (2017). “¿Qué aportan los bienes intangibles a la administración pública?”. En: Canel-Crespo, María-José; Piqueiras-Conlledo, Paloma; Ortega-Jarrín, Gabriela (eds.). La comunicación de la administración pública: conceptos y casos prácticos de bienes intangibles. Madrid: Instituto Nacional de Administración Pública, pp. 29-50. ISBN: 9788473516181

Capriotti, Paul; Oliveira, Andrea; Costa, Lluís (2016). “La importancia estratégica de la investigación preliminar de los públicos para los departamentos de comunicación de las empresas energéticas en España". Revista internacional de relaciones públicas, v. 6, n. 12, pp. 25-42.

https://doi.org/10.5783/RIRP-12-2016-03-25-42 
Capriotti, Paul; Pardo-Kuklinski, Hugo (2012). "Assessing dialogic communication through the internet in Spanish museums". Public relations review, v. 38, n. 4, pp. 619-626.

https://doi.org/10.1016/j.pubrev.2012.05.005

Carretón-Ballester, Carmen (2014). "La molécula conductual de relaciones públicas en la comunicación gubernamental con los inmigrantes en España”. Revista latinoamericana de comunicación, n. 126, pp. 42-56.

https://core.ac.uk/download/pdf/32325606.pdf

Castillo-Esparcia, Antonio (2010). Introducción a las relaciones públicas. Málaga: Instituto de Investigación en Relaciones Públicas. ISBN: 9788461424481

https://www.uma.es/media/files/libropr_1.pdf

Castillo-Esparcia, Antonio; Almansa-Martínez, Ana (2002). "El gabinete de comunicación en el ámbito local". En: López-Lita, Rafael; López-Beltrán, Francisco; Durán-Mañes, Ángeles (coords.). La prensa local y la prensa gratuita. CasteIlón: Publicaciones de la Universitat Jaume I, pp. 383-392. ISBN: 848021399 X

Corcoy-Rius, Marta (2018). "La aplicación efectiva de la transparencia en las instituciones". ACOP Papers, n. 13. https://compolitica.com/wp-content/uploads/2018/10/ACOPPapersNo13.pdf

Criado, Juan-Ignacio (2016). "Las administraciones públicas en la era del gobierno abierto. Gobernanza inteligente para un cambio de paradigma en la gestión pública”. Revista de estudios políticos, n. 173, pp. 245-275.

https://doi.org/10.18042/cepc/rep.173.07

Criado, Juan-Ignacio; Rojas-Martín, Francisco (eds.) (2015). Casos de éxito en redes sociales digitales de las administraciones públicas. Barcelona: Generalitat de Catalunya. Escola de l'Administració Pública de Catalunya. ISBN: 9788460655572 http://eapc.gencat.cat/web/.content/home/publicacions/col_leccio_obres_digitals/20_casos_exito_redes_sociales/ Casos-de-exito-en-RSD-de-las-AA-PP.pdf

Criado, Juan-Ignacio; García-Alonso, Roberto (2012). “¿Democracia 2.0? Un análisis del potencial deliberativo de la blogosfera política". Revista de estudios políticos, n. 155, pp. 71-99.

https://recyt.fecyt.es/index.php/RevEsPol/article/view/40053

Cutlip, Scott M.; Center, Allen H.; Broom, Glen M. (2001). Relaciones públicas eficaces. Barcelona: Gestión 2000. ISBN: 9788480885737

Delgado-Morales, Francisco (2015). "Sistemas de medición y transparencia en los ayuntamientos". Revista española de la transparencia, n. 0, pp. 12-17.

https://drive.google.com/file/d/OBzZV66dM4HCTOTFuY1FOVDRxdOk/view

España (1985). “Ley 7/1985, de 2 de abril, reguladora de las bases del régimen local”. BOE, n. 80, 3 abril. https://www.boe.es/buscar/act.php?id=BOE-A-1985-5392

España (2013). “Ley 19/2013, de 9 de diciembre, de transparencia, acceso a la información pública y buen gobierno”. $B O E$, n. 295, 10 diciembre.

https://www.boe.es/buscar/act.php?id=BOE-A-2013-12887

España (2015). “Ley 2/2015, de 2 abril, de transparencia, buen gobierno y participación ciudadana de la Comunitat Valenciana". BOE, n. 100, 27 abril.

https://www.boe.es/buscar/pdf/2015/BOE-A-2015-4547-consolidado.pdf

Esteve-Mallent, Katia (2018). “Poder, participación y nuevos medios de comunicación: ¿uutopía o distopía política?”. En: Aznar, Hugo; Pérez-Gabaldón, Marta; Alonso, Elvira; Edo, Aurora (eds.). El derecho de acceso a los medios de comunicación. II. Participación ciudadana y de la sociedad civil. Valencia: Tirant, pp. 39-57. ISBN: 9788417508449

Fernández-Cavia, José; Huertas-Roig, Asunción (2009). Redacción en relaciones públicas. Madrid: Pearson Educación. ISBN: 9788483224953

Fernández-Dutto, Matías (2006). “Relaciones públicas 2.0". Razón y palabra, n. 52. http://www.redalyc.org/articulo.oa?id=199520719013

Fernández-Ramos, Severiano (2018). “La transparencia pública: pasado, presente y futuro”. Revista aragonesa de administración pública, n. 51, pp. 213-243.

http://www.nuevoderechourbanistico.es/wp-content/uploads/2018/12/revista-aragonesa-administracion-51.pdf

Garnett, James L. (2011). "Public administrative communication". Public administration review's. Foundations of public administration.

http://citeseerx.ist.psu.edu/viewdoc/download?doi=10.1.1.462.9858\&rep=rep1\&type=pdf 
Gómez-Camarero, Carmen (2003). "Las nuevas formas de comunicación de la administración con el ciudadano”. Anales de documentación, n. 6, pp. 109-119.

https://revistas.um.es/analesdoc/article/view/2011/2001

Grunig, James E.; Hunt, Todd (2003). Dirección de relaciones públicas. Barcelona: Gestión 2000. ISBN: 9788480889483

Herrero-Gutiérrez, Francisco-Javier; Martínez-Vallvey, Fernando; Tapia-Frade, Alejandro; Rey-García, Pablo; Cabezuelo-Lorenzo, Francisco (2017). "Transparencia en el sector público a través de salas de prensa online. Gestión de recursos colectivos y su información en webs municipales". El profesional de la información, v. 26, n. 3, pp. 421-429.

https://doi.org/10.3145/epi.2017.may.08

Jiménez, Sergio (2017). Análisis de los portales de transparencia. Guía metodológica.

https://analiticapublica.es/guia-transparencia

Kent, Michael L.; Taylor, Maureen (1998). "Building dialogic relationships through the World Wide Web". Public relations review, v. 24, n. 3, pp. 321-334.

https://doi.org/10.1016/S0363-8111(99)80143-X

Kirat, Mohamed (2007). "Promoting on-line media relations: Public relations departments' use of internet in the UAE". Public relations review, v. 33, n. 2, pp. 166-174.

https://doi.org/10.1016/j.pubrev.2007.02.003

Kovach, Bill; Rosenstiel, Tom (2012). Los elementos del periodismo. Barcelona: Aguilar. ISBN: 9788403012394

Lago-Peñas, Ignacio (2008). La lógica de la explicación en las ciencias sociales. Una introducción metodológica. Madrid. Alianza Editorial. ISBN: 9788420691176

Luhmann, Niklas (1978). Stato di diritto e sistema sociale. Napoli: Guida. ISBN: 9788878350373

Manfredi-Sánchez, Juan-Luis (2017). “Indicadores de transparencia y buen gobierno de las webs municipales españolas". Estudios sobre el mensaje periodístico, v. 23, n. 1, pp. 477-488.

https://doi.org/10.5209/ESMP.55608

McCombs, Maxwell E. (2006). Estableciendo la agenda. El impacto de los medios en la opinión pública y en el conocimiento. Barcelona: Paidós. ISBN: 9788449318696

McCombs, Maxwell E.; Shaw, Donald L. (1972). "The agenda-setting function of mass media”. Public opinion quarterly, v. 36, n. 2, pp. 176-187.

https://doi.org/10.1086/267990

Míguez-González, María-Isabel (2010). Los públicos de las relaciones públicas. Barcelona: UOC. ISBN: 9788497881067

Molina-Rodríguez-Navas, Pedro; Simelio-Solà, Núria; Corcoy-Rius, Marta (2017). “Metodologías de evaluación de la transparencia: procedimientos y problemas". Revista latina de comunicación social, n. 72, pp. 818-831.

https://doi.org/10.4185/RLCS-2017-1194

Monfort, Abel; Villagra, Nuria; López-Vázquez, Belén (2019). “Exploring stakeholders' dialogue and corporate social responsibility (CSR) on Twitter". El profesional de la información, v. 28, n. 5, e280513.

https://doi.org/10.3145/epi.2019.sep.13

Moreno-Sardà, Amparo; Corcoy-Rius, Marta; Molina-Rodríguez-Navas, Pedro; Toledano-Buendía, Samuel; Vera-Balanza, María-Teresa; Rodríguez-Breijo, Vanessa; Simelio-Solà, Núria (2015). “Comparativo de 230 webs de ayuntamientos de municipios de más de 20.000 habitantes". En: Molina-Rodríguez-Navas, Pedro (coord.). Transparencia de la comunicación pública local. El mapa Inforparticipa. Cuadernos artesanos de comunicación, n. 78. La Laguna: Latina, pp. 149-157. ISBN: 9788415698951

https://ddd.uab.cat/pub/llibres/2015/200271/cac78_publicado.pdf

Moreno-Sardà, Amparo; Molina-Rodríguez-Navas, Pedro; Simelio-Solà, Núria (2017). "Impacto de la legislación sobre la transparencia en la información publicada por las administraciones locales". El profesional de la información, v. 26, n. 3, pp. 370-380.

https://doi.org/10.3145/epi.2017.may.03

Otero-Alvarado, María-Teresa; Pulido-Polo, Marta (2018). Planificación y técnicas de relaciones públicas. Madrid: Síntesis. ISBN: 9788491712299

Pérez-Tornero, José-Manuel; Giraldo-Luque, Santiago; Tejedor-Calvo, Santiago; Portalés-Oliva, Marta (2018). “Propuesta de indicadores para medir las competencias de alfabetización mediática en las administraciones públicas". El profesional de la información, v. 27, n. 3, pp. 521-536.

https://doi.org/10.3145/epi.2018.may.06 
Peytibi, Xavier (2016). "Nuevas tendencias en comunicación institucional local”. Más poder local, n. 28, pp. 32-36. http://www.maspoderlocal.es/files/articulos/268-F5790bd6f2681469103471-articulo-1.pdf

Puig-Picart, Toni (2003). La comunicación municipal cómplice con los ciudadanos. Barcelona: Paidós. ISBN: 97884493 14490

Rebolledo, Marta; Zamora-Medina, Rocío; Rodríguez-Virgili, Jordi (2017). "Transparency in citizen participation tools and public information. A comparative study of the Spanish city councils' websites". El profesional de la información, v. 26, n. 3, pp. 361-369.

https://doi.org/10.3145/epi.2017.may.02

Rodríguez-Breijo, Vanessa; Álvarez-Nobell, Alejandro; Moreno-Sardá, Amparo (2014). “Relaciones públicas para la participación ciudadana en el seguimiento y la evaluación de la gestión de los principales gobiernos locales de Aragón. El empleo de la web en la administración de los recursos colectivos". En: Carretón-Ballester, Carmen; Matilla-Serrano, Kathy (coords.). La conducta interactiva de los públicos para las relaciones eficaces. Zaragoza: Universidad San Jorge, pp. 35-57. ISBN: 9788494185069

Rojas-Orduña, Octavio-Isaac (2008). Relaciones públicas: La eficacia de la influencia. Madrid: Esic. ISBN: 97884735 64170

Seitel, Fraser P. (2002). Teoría y práctica de las relaciones públicas. Madrid: Pearson. ISBN: 9788420535104

Túñez-López, Miguel (2015). “Modelo de simetría interactiva en comunicación organizacional”. Revista mediterránea de comunicación, v. 6, n. 2, pp. 5-7.

https://doi.org/10.14198/MEDCOM2015.6.2.14

Vañó-Sempere, Mayte (2015). “Estrategias de implantación y gestión de las redes sociales en le sector público". En: Criado, Juan-Ignacio; Rojas-Martín, Francisco. Casos de éxito en redes sociales digitales de las administraciones públicas. Generalitat de Catalunya: Escola de l’Administració Pública de Catalunya, pp. 97-113. ISBN: 9788460655572 http://eapc.gencat.cat/web/.content/home/publicacions/col_leccio_obres_digitals/20_casos_exito_redes_sociales/ Casos-de-exito-en-RSD-de-las-AA-PP.pdf

Vázquez-Gestal, Montserrat; Fernández-Souto, Ana-Belén (2014). “El profesional de las relaciones públicas en Galicia: el caso de los principales ayuntamientos gallegos". Revista internacional de relaciones públicas, v. 6, n. 7, pp. 25-38. https://doi.org/10.5783/RIRP-7-2014-03-25-38

Wilcox, Dennis L.; Cameron, Glen T.; Xifra, Jordi (2012). Relaciones públicas: estrategias y tácticas. Madrid: Pearson Educación. ISBN: 9788483228135

Xifra, Jordi (2003). Teoría y estructura de las relaciones públicas. Madrid: Mc Graw Hill. ISBN: 9788448139896

Xifra, Jordi (2011). Manual de relaciones públicas e institucionales. Madrid: Tecnos. ISBN: 9788430952670

Profesional de la información

\section{http://www.elprofesionaldelainformacion.com}

\section{Bienvenido a $P$}

Revista cientifica internacional 